\title{
Embracing impressionism: revealing the brush strokes of interpretive research $^{1}$
}

John Boswell, Institute for Governance and Policy Analysis, University of Canberra, and University of Southampton

Jack Corbett, Griffith University and the Australian National University

\section{Introduction}

Key figures in the interpretive approach to studying politics and policy have bristled at the mainstream notion that such research is 'impressionistic'. Hendrik Wagenaar (2011, 251), in his overview of the core features of interpretive policy analysis, confronts this sticky prejudice:

Those who are critical of interpretive approaches generally tend to see them as unsystematic, impressionistic, 'soft' ways of doing scientific research.

Dvora Yanow $(2006,100)$ is even more emphatic:

'Interpretive' does not mean 'impressionistic'.

For these and other key pioneers (eg. Ospina and Dodge 2005b; Bevir and Rhodes 2010), interpretive research is not impressionistic, but 'systematic'.

Our essay is motivated by the disconnect we felt, as newcomers to this craft, between these claims to systemacity and our own experiences. We had drawn on the tools, techniques and justifications of key interpretive pioneers like Wagenaar and Yanow in

${ }^{1}$ This paper is forthcoming in slightly amended form as a Forum contribution in Critical Policy Studies. 
conducting intense, laborious and technically demanding research. But we remained uneasy. Our analysis seemed to rely as much on lingering impressions from the field as it did on any methodical accretion of insights. Our findings, however well received by academic peers and practitioners, represented only a partial, stylized account of the complexity swirling around in our heads. It did not feel systematic at all. Were we doing it wrong? Or, are there alternative ways of thinking about the practice of interpretive research that celebrate, rather than downplay, the impressionistic nature of this craft?

\section{A systematic craft?}

Several scholars have spoken about an 'interpretive turn' in the study of the political ${ }^{2}$, with a significant minority of researchers moving away from trying to explain the political world as it really is, and towards investigating the ways in which actors make sense of the political world and how their perceptions relate to political practices. As part of the conceptual maturation of this movement, a distinct set of standards by which interpretive research should be conducted and judged has developed. The authors who have advanced these standards the furthest are Ospina and Dodge (see Dodge, Ospina and Foldy 2005; Ospina and Dodge 2005a; 2005b), Bevir and Rhodes (2010), Wagenaar (2011) and Yanow, either alone (see 2006; 2007; 2009) or in combination with Schwartz-Shea (2012). There are nuanced differences in respect of the terminology these authors adopt, but by and large they present a similar range of

\footnotetext{
${ }^{2}$ For overviews, see Yanow and Schwartz-Shea (2006), especially their introductory chapter, as well as the various perspectives in Finlayson et al. (2004) and the more recent special issue to mark the end of RAW Rhodes' editorship of Public Administration.
} 
criteria: that the validity of the research rests on its plausibility with the immediate practitioners to whom it relates and the academic audiences it addresses; that the generation of findings is by necessity iterative, entailing constant and messy interaction between theory and practice; that the research should be based in rich immersion in data, as well as in the academic literatures to which these data relate, through which the outcomes of interpretation — codes, categories, themes, stories— crystallise.

We have found many of these criteria extremely useful when thinking about our research. Where we take issue, however, and the point on which our argument turns, is with the depiction of what this crystallisation represents: we argue that by attempting to reclaim the term 'systematic' as an overarching descriptor, leading figures envisage a version of interpretivism that we, and possibly others like us, do not experience. So, we present a critique of interpretive research from 'within' by drawing reflexively on our own research practice. Our hope is that this will provoke others to do the same.

As the term 'reclaim' would suggest, no one uses 'systematic' in the rigid sense typically employed by positivists - there is room for creativity, spontaneity and iteration. Instead, the key pioneers of this movement see research as systematic in the sense that it involves a methodical progression towards a more coherent and convincing account of the phenomenon under investigation. Wagenaar $(2011,22)$ explains:

Through a painstaking and systematic process of imaginative induction, we transform our crude earlier interpretations/observations into better, higher- 
order more enduring interpretations that somehow capture the meaning of what has transpired.

Likewise, Yanow $(2006,102)$ describes the work of interpretation as an 'interpretive dance' towards a deeper and more fulfilling understanding, offering the following analogy:

The most exacting descriptions of forms of interpretive analysis describe a kind of indwelling with one's data: whether using index cards held in the hand or large sheets of paper tacked to the walls, the process entails reading and rereading again—musing, in an abductive way—until, in the light of prior knowledge of the theoretical literature or the empirical data, or both, something makes sense in a new way. The experience feels like part of a thousand-piece jigsaw puzzle suddenly fitting together...

There are aspects of this analogy that we find appealing. The notion of a jigsaw puzzle hints at the fact that interpretation must inevitably be framed or restricted; it recognizes that there is limited space in which to record interpretations and typical constraints about the ways in which this might occur; it also acknowledges that interpretive researchers are working with different sorts of materials (theoretical and empirical), and captures the sense of intellectual creativity involved in trying to link them together.

But, in our experience, the creative work of interpretation is not as organic as this analogy suggests. The 'pieces' of interpretive research do not always fit together neatly. They are forced together by the researcher, often in service of a cleaner or more interesting account. Moreover, there is no expected or ideal end result to 
interpretive research. Its final form is in no way obvious, and it can take multiple, conflicting forms. Finally, and most fundamentally, the jigsaw puzzle analogy overlooks the fact that there are not a thousand pieces, but an infinite number. This is true of both the data and the academic literature; the data on which researchers draw is near unlimited and in no ways self-evident, as are the links they can make with scholarly ideas and concerns.

The limitations of the jigsaw puzzle analogy are indicative of the limitations of the shared conception among leading figures in this movement, for whom we use Yanow and Wagenaar as influential exemplars, that doing interpretation entails a systematic progression towards a superior analysis. In practice, this stance risks becoming yoked to its 'counter identity' - more concerned with its positivist 'other' than itself (Corbett and Boswell forthcoming). We argue, in contrast, that the crystallisation around particular ways of making sense is not always the 'Eureka!' moment that such a conception implies, and that its outcomes are considerably more unstable and contestable than such a process would deliver: in our experience, a more apt descriptor for the work involved is impressionistic, and a more apt analogy is the creation of impressionist art. $^{3}$

\footnotetext{
3 Though we use this analogy to be provocative in the context of the interpretive policy studies literature, it is important to acknowledge that it is not an entirely new way of thinking about research in anthropology (van Maanen 1988), which has been so influential in the interpretive movement. Note, though, that where van Maanen sees impressionism as a particular, rare and conscious mode of representing fieldwork, we are making a somewhat broader claim in this paper.
} 


\section{A provocative analogy: interpretation as impressionism}

We do not intimate here that in their repudiation of the label 'impressionistic' that Yanow, Wagenaar or anyone else uses this term as a referent to the art world. Taken in context, their usage is more in line with the everyday sense of impressionistic — being vague, hastily reached or uninformed. And, although the apparent contrast works well as a rhetorical device, we do not, in picking up on this term, mean to appeal to these connotations. Instead, we reclaim the meaning of impressionism as associated with the revolutionary art movement of the $19^{\text {th }}$ century. The 'impressionists' went against the conventions of the time, which upheld the virtue of creating smooth portraits of idyllic subjects, and tried instead to capture life as they saw it. Rather than focus on the noble or divine, for instance, they took their inspiration from everyday settingsnatural and social—and tried to capture the unique 'impression' of being there. They set about their work in a way that was often informed by particular stylistic motifsto recreate the play of light—which, in turn, were enabled by particular techniquesespecially the use of thick, textured, contrasting brush strokes (Clancy 2003). But impressionism was not a conformist school with a method to be formulaically applied according to a set program. It was a general orientation with a set of tools that the artist could draw upon with innovative virtuosity (Herbert 1988). This approach quickly spread from painting to other forms of artistic expression, such as sculpture, literature and music.

Here we can hardly delve deeply into art historiography. ${ }^{4}$ Our aim is to gain a better understanding of what impressionism entails. We do so with a view to arguing that it

\footnotetext{
${ }^{4}$ It is important to acknowledge here that this popular account has been challenged by an alternative view of impressionism as a much more methodical enterprise (a
} 
represents an apt analogy for describing the process of doing and communicating interpretation. As such, our focus here is limited to the generic features uniting impressionism across the various artistic pursuits. These include:

(a) a challenge to orthodoxy both in style and content, manifested especially in a desire to objectify immediate experience;

(b) the aim of shedding new light on the familiar context under examination;

(c) a coherent method, but not one that is applied systematically;

(d) the sacrifice of detail in the pursuit of recreating the appropriate feel and mood; and

(e) an end product which represented a singular, ephemeral impression of the phenomenon under examination.

We do not anticipate much opposition in relation to the proposition that (a) above captures an important aspect of interpretive research. Indeed, echoing our earlier ‘counter identity’ point, interpretive researchers typically approach their task in a way that consciously defies contemporary orthodoxy in political science, taking an interest in under-studied phenomena or making an effort to approach familiar phenomena in very different ways (Bevir and Rhodes 2010). Most are preoccupied with understanding action, and their primary interest is in interpreting how everyday political phenomena are perceived by the actors involved, and what practices these perceptions bring about. Most are comfortable in acknowledging the personal,

dichotomy that mirrors the challenge we hope to offer to the established account of interpretive research). We do not seek to unpack this at all, but simply to make clear that it is this popular image that we have in mind. 
subjective nature of their own interpretation (as the researcher) of these interpretations (of the participants), too (Hay 2011).

The notion that (b) above applies to doing interpretation also resonates with some existing work in this area. Indeed, this is a point Yanow (2006) makes, for instance, in the section highlighted earlier-putting together pieces in the puzzle represents making sense of some event or phenomenon in a new and interesting way. Bevir (2011, 191), in his defense of public administration as storytelling, is more explicit: Public administration is less about discovering general rules, than about seeing new aspects of cases and relating them to our more abstract concepts.

However, the point at which our analogy becomes controversial is in relation to the notion that (c) interpretive research need not and often does not involve the systematic application of method. To be clear, in extending this analogy we accept that there is most certainly a coherent method (or set of methods) that underpins interpretive research. Just as impressionist painters drew on new techniques and developments in colour theory to produce artwork in line with a particular orientation towards creating art, so too do interpretive researchers draw on tools and techniques coherently aligned with epistemological and ontological convictions towards doing social science. The point we want to make, though, is that as with the production of impressionist art, the elements or components that collectively comprise or are affiliated with this coherent method are typically applied in an idiosyncratic and even spontaneous, rather than systematic, manner.

We acknowledge that interpretive researchers might sketch out a research design with various compartments or components—a desk research phase, a data collection phase, 
and so on (see Schwartz-Shea and Yanow 2012). We even accept that some of these components, at least for some of the time, operate in a way that could be described as systematic. ${ }^{5}$ However, in practice these apparently systematic phases are typically disrupted and reworked to such an extent that we have not experienced them as approaching anything near a systematic whole.

To start with, any such systematic work plan is in our experience always infused with, and undermined by, moments of impressionistic intuition. A feisty encounter, a lingering ambiguity, an awkward disquiet, something unexpectedly funny or poignant—-these are all moments and sensations that speak to the disruption and dissolution of the systematic or stepwise analytical progression in Hajer's or Wagenaar's accounts.

Moreover, transforming ideas, however systematically developed, into readable print involves a constant, messy process of shifting and refinement (see van Maanen 1988, Law 2004 or Yanow 2009 for lengthy treatments). As Law in particular stresses, writing up interpretive research typically involves the messy fusion of methodical insights with sudden and exciting recollections of particular impressions—warm, funny or discomforting quotes or episodes which escaped the initial 'systematic' analysis but offer more colorful or poignant evidence of the point. It involves disentanglement of these initial insights, which is sometimes a painful exercise in 'letting go' of particular ideas or outlying events and episodes so as to generate a more parsimonious account. And it involves frustrating searches back through reams of interview data and observations notes for evidence to support new ideas that

${ }^{5}$ For illustrations, see Hajer's (2006) 'stepwise' account of doing discourse analysis or Wagenaar’s (2011) 'systematic’ approach to analysing interview data. 
spontaneously arise. These bouts of confusion, frustration, angst and inspiration speak to a craft that neither resembles, nor feels like, a systematic progression.

There may also be strong opposition to the related notion (d) that interpretive research produces a stylized rather than faithful representation. To be clear, we acknowledge that no one claims interpretive research entails 'getting the facts right' in the first place (Schwartz-Shea and Yanow 2012). Indeed, most researchers drawn to interpretivism and its associated tools and techniques subscribe to a philosophy that eschews the possibility of stable, objective facts and singular, true stories anyway (Finlayson et al. 2004). Our point here is more about the limited capacity of interpretive researchers to convey rich contextual detail in the products of their work. Though interpretive researchers typically see themselves as generating 'thick descriptions' that give a comprehensive analysis of the context (eg. van Hulst 2008; Schwartz-Shea 2006)—a claim understandable relative to work in the positivist tradition - they too must be selective about the finer details they incorporate and give meaning to. They cannot recount the full complexity of the phenomena in question, either in terms of the data they are focusing on or the academic literature on which they are drawing. ${ }^{6}$ Instead, communicating interpretation involves conveying vivid, rich details that best capture what researchers deem to be the most important features of their analysis. Anecdotes, examples and quotes are chosen specifically to give

\footnotetext{
${ }^{6}$ And forging the relationship between the two often involves forcing or stylizing one or both to generate a compelling argument-indeed, a good case in point is our stylized account of impressionist art, which, as we suggested above, some learned art historians would doubtless take issue with as lacking systemacity (though see van Maanen 1988: 101-106 or Merleau-Ponty 1964: 11-12 for equally, but differently, stylized accounts).
} 
readers a better feel for the context, as well as to better underpin the broader theoretical argument that the researcher is trying to make.

This is not to say that interpretive researchers need not be concerned with the 'reality' of the world of politics and policy—-that all that matters is the aesthetics of composition. After all, impressionist artists took 'nature as their model', and were motivated by the desire to better capture such 'reality' (Merleau-Ponty 1964). Indeed, on the contrary, we agree with Bevir and Rhodes (2010) and Torgerson (2013) who make clear that a focus on interpretation or opinion, respectively, does not entail a descent into relativism: plausibility as governed by intersubjective agreement must remain an important criterion of interpretive research. In contrast to this perpetual concern that interpretive scholars have abandoned the reality of the world, our more modest point is that, as in any research tradition, such intersubjectively determined standards of plausibility do not solely rest on fine-grained accuracy, and that we often make trade-offs between detail and accuracy on the one hand and unveiling and communicating broader truths on the other. This process is often, we suggest, impressionistic: impressionistic researchers not only diligently describe and conscientiously interpret the subject at hand, but their work is further shaped by judgments, conscious or unconscious, about the impression their account will make on those who read it.

Taken as a whole, we anticipate that the conclusion, in (e) above, that the products of interpretive research may therefore represent singular, ephemeral impressions, will be the most controversial. Indeed, as we have already shown, leading scholars in the interpretive turn in the study of politics and policy have been quick to distance themselves from charges of being 'impressionistic'. To clarify, in invoking the term 
impressionism, our argument here is not that the mainstream critics of interpretivism are right - that this type of research is more haphazard or poorly informed than any other, or that its products are less worthy. Our argument is that the collective features described above mean that the products of interpretive research, like those of impressionist art, suggest only a partial and fleeting perception of the world, in the sense that they can only ever convey a limited impression of the phenomenon under investigation. They are, after all, produced by one researcher or a small team of researchers, most often working with limited access, a finite time window and substantial pressures to produce outcomes, as Wildavsky (1989: 13) reflects:

The imposition of order on recalcitrant material, which we optimistically call knowledge, is a sometimes thing, hard won, temporary, and artificial, like the rest of civilization.

\section{What might embracing impressionism mean?}

To reiterate, the point of extending the analogy is not to say that interpretive research is more haphazard than other kinds of research. We believe 'the art and craft of policy analysis’ as Wildavsky more famously said elsewhere is in any tradition impressionistic along many of the dimensions we identify. What distinguishes interpretive research, however, is a commitment to reflexivity which aligns it with the most revolutionary and challenging aspect of impressionism — the move to reveal the brush strokes underlying any composition.

We want to conclude by arguing that, in this vein, interpretive researchers for whom this analogy resonates ought to embrace, rather than shy away from or cover over, the impressionism they practice. We suggest that a more reflexively 'impressionistic' 
approach to interpretive research, and some of the changes this might engender in practice, might strengthen rather than weaken the stance of interpretivism in the study of politics and policy more broadly.

For the validity of the interpretive approach?

This final aim may seem to stretch credulity for those feeling marginalized from the mainstream anyway: embracing a term like 'impressionism' seems to run the risk of permanent banishment from the realm of serious social science. However, what we are advocating is less that everyone publicly wear this particular label, and more acknowledgment of the substance of the point. One of the most stinging criticisms is that interpretive research remains opaque in practice (see, for example, the criticisms in Marsh and Hall 2007). Indeed, in line with conceptual assertions about the systemacity of this craft, it is common in practical applications of interpretive research—-take some of our own work (Boswell et al. 2013; Corbett 2013)—-to see categories of interpretation retrospectively applied as if it had been a hydraulic process all along. Instead, interpretive researchers might embrace the impressionism that they practice. When examined up close, readers should be able to appreciate the 'brush strokes’ of their work.

One step along this path is to be more transparent about where interpretations come from by inviting interested readers into the process. Interpretive researchers could, for instance, make their data and the different iterations of their analysis available for scrutiny, in the same way that some positivist researchers are starting to grant others 
access to their raw material and analyses. ${ }^{7}$ Skeptics will be quick to point out that this may not always be possible, for both pragmatic and ethical reasons, although researchers doing such work may be able to think of creative alternatives. ${ }^{8}$ In any case, moving to open up the process of interpretation would be an important gesture that would better confront and reflect the experience of doing interpretation both for the researcher and the audience.

Another step might involve actively embracing partiality and dissonance. Interpretive researchers might, for instance, go out of their way to report on distinct and potentially even incompatible impressions of the relationship of their data to theory, either as independent researchers or as different parts of a collaborative team. This is not to say such an idea is novel—it is indeed a key tenet of good interpretive research according to Schwartz-Shea and Yanow (2012)—nor that it does not already happen to some extent anyway. There are, in fact, many examples of interpretive researchers mining the same data for different purposes. But those who do so generally present these distinct interpretations as having stemmed from a focus on different phenomena or research questions (again, see our own work for examples: cf. Boswell 2014 with Boswell and Corbett 2014). They do not show competing or overlapping interpretations of the same phenomena and questions. Persistent norms and incentives discourage interpretive researchers in politics and policy, like us, from

\footnotetext{
${ }^{7}$ This was something called for in a number of contributions to a special issue of PS: Political Science and Politics in 1995, and which has subsequently occurred to some extent in parts of the broader discipline. It is also not unheard of among interpretive researchers. Maynard-Moody and Musheno (2003) provide detailed interview transcripts resulting from their highly influential study of street-level bureaucrats, for instance.

8 See, for example, the effort to make qualitative data from interviews conducted with indigenous people in Australia more broadly available for scholarly use at www.atsida.edu.au.
} 
acknowledging and representing the discordant nature of our impressions. ${ }^{9}$ This need not be the case.

For the relationship between research and policy?

A more consciously impressionistic approach can also strengthen relationships with the policy actors who are the subject of interpretive research. Though often motivated by, and almost always involving, deep engagement in the practice of policy and politics, researchers use the meanings and beliefs of the actors involved to serve a particular purpose and to generate a particular impression. Again, Heclo and Wildavsky (1974, xiii), important forebears of an interpretive approach (see Weller 2014), sum this up succinctly:

The cure for ignorance about how something gets done is to talk with those who do it; the cure for the confusion which then replaces the ignorance is to think about what you are told. Almost all of the information for this book has been garnered from those who are or have been participants in the expenditure process. But the interpretation and arrangement of the answers are our own.

A consciously impressionistic orientation can confront the messy, partial nature of conducting research and therefore invite practitioners into discussion of claims and findings on a more equal footing at the 'back end' of the process. Acknowledging that researchers and practitioners simply have impressions of different types can help

\footnotetext{
${ }^{9}$ Once again looking to ethnography, see Wolf 1992 for an outstanding example of what recognising and addressing such dissonance can look like in a single monograph.
} 
realise co-production and embed relevance as core features of the research process (see Ospina and Dodge 2005b).

For this community of practice?

Most significantly of all, embracing impressionism can open up the 'black box' of interpretive research for those attracted to the craft, strengthening the movement from within. For those who adopt an interpretive approach, like ourselves, there can be an initial (and perhaps ongoing) sense of inadequacy. Some recent work has made valuable progress in this regard, revealing, for example, the personal angst that can be associated with doing and analyzing elite interviews (Hendriks 2007), the personal motivations that lead researchers to pursue particular interests and angles (see the introductions to each chapter in Yanow and Schwartz-Shea 2006), or the avowedly low-tech tools and strategies that can be crucial to interpretation (like the 'index cards' Yanow 2006 cited earlier). We hope this essay complements this scholarship by shining light on some of the difficulties and anxieties associated with doing and communicating interpretation.

Yet, of course, it is far from the final word. Our 'impressionism' analogy offers an alternative vision of how interpretive research can be conducted and how it might be received by scholarly and practitioner communities, prompting internal reflection and critique. But there are most certainly a multitude of other ways of thinking about interpretation that may resonate more strongly with those engaged in this scholarly community. We hope that our contribution is provocative, stoking debate and discussion as to how we go about this craft, and how we judge its quality. 


\section{References}

Bevir, M and Rhodes, RAW 2010, The state as cultural practice, Oxford and New York, Oxford University Press.

Bevir, M 2011, 'Public administration as storytelling’, Public Administration, vol. 89, no. 1, pp. 183-95.

Boswell, J, Niemeyer, SJ and Hendriks, CM 2013, 'Julia Gillard's citizens' assembly proposal for Australia: a deliberative democratic analysis’, Australian Journal of Political Science, 48, (2), 164-178.

Boswell, J 2014, “Hoisted with our own petard': evidence and democratic deliberation on obesity’, Policy Sciences, DOI: 10.10072/s11077-014-9195-4.

Boswell, J and Corbett, J 2014, 'Stoic democrats? Anti-politics, elite cynicism and the policy process’, to be presented at Policy \& Politics Conference, Bristol (available from authors on request).

Corbett, J 2013, “Everybody knows everybody’: practising politics in the Pacific Islands.' Democratization (ahead-of-print), 1-22.

Corbett, J and Boswell, J forthcoming, 'An Antipodean history of interpretation', Australian Journal of Public Administration.

Clancy, JI (ed.) 2003, Impressionism: historical overview and bibliography, Nova Science Publishers, New York.

Dodge, J, Ospina, S and Foldy, EG 2005, ‘'Integrating rigor and relevance in public administration scholarship: the contribution of narrative inquiry', Public Administration Review, vol. 65, no. 3, pp. 286-300. 
Finlayson, A, Bevir, M, Rhodes RAW, Dowding, K and Hay, C, The interpretive approach in political science: a symposium, British Journal of Politics and International Relations, vol. 6, no. 2, pp. 129-164.

Hajer, M 2006, ‘Doing discourse analysis: coalitions, practices, meaning’, in M van den Brink and T Metze (eds.), Words matter in policy and planning: discourse theory and method in the social sciences, KNAG/Nethur, Utrecht, ND, pp. 6574.

Heclo, H and Wildavsky, AB 1974, The private government of public money: community and policy inside British politics, Macmillan, London.

Hendriks, CM 2007, 'Praxis stories: experiencing intepretive policy research’, Critical Policy Studies, vol. 1, no. 3, pp. 278-300.

Herbert, RE 1988, Impressionism: art, leisure and Parisian society, Yale University Press, New Haven.

Law, J 2004, After method: mess in social science research, New York, Routledge. Marsh, D and Hall, M 2007, 'The British political tradition: explaining the fate of New Labour’s constitutional reform agenda', British Politics, vol. 2, pp. 215238.

Merleau-Ponty, M 1964, Sense and Non-sense, Northwestern University Press, Chicago.

Maynard-Moody, S and Musheno, M 2003, Cops, teachers, counselors: stories from the front lines of public service, University of Michigan Press, Ann Arbor.

Ospina, S and Dodge, J 2005a. 'It's about time: catching method up to meaning-the usefulness of narrative inquiry in public administration research', Public Administration Review, vol. 65, no. 2, pp. 143-157. 
Ospina, S and Dodge, J 2005b, 'Narrative inquiry and the search for connectedness: practitioners and academics developing public administration scholarship’, Public Administration Review, vol. 65, no. 4, pp. 409-423.

Schwartz-Shea, P 2006, ‘Judging quality: evaluative criteria and epistemic communities', in D Yanow and P Schwartz-Shea, Interpretation and method: empirical research methods and the interpretive turn, ME Sharpe, New York. Schwartz-Shea, P and Yanow D 2012, Interpretive research design: concepts and practices, Routledge, New York.

Torgerson, D 2013, 'Policy as a matter of opinion', Critical Policy Studies, vol. 7, no. 4, pp. 449-454.

Wagenaar, H 2011, Meaning in action: interpretation and dialogue in policy analysis, ME Sharpe, New York.

Wildavsky, A. 1989, Craftways: On the Organization of Scholarly Work. Transaction Publishers, New Brunswick, USA and London, UK.

Wildavsky, A. 1979, Speaking truth to power: the art and craft of policy analysis, Little Brown, Boston.

Weller, P forthcoming, 'Anticipating interpretivism: Heclo and Wildavsky as pioneers?', Australian Journal of Public Administration.

Wolf, M 1992, A thrice told tale: feminism, postmodernism and ethnographic responsibility, Stanford University Press, Stanford.

van Hulst, M 2008, Town hall tales, Eburon Publishers, Delft (The Netherlands). van Maanen, J. 1988, Tales of the field: on writing ethnography, University of Chicago Press, Chicago. 
Yanow, D and Schwartz-Shea, P (eds.) 2006, Interpretation and method: empirical research methods and the interpretive turn, ME Sharpe, New York.

Yanow, D 2006, 'Neither rigorous nor objective? Interrogating criteria for knowledge claims in interpretive science’, in D Yanow and P Schwartz-Shea (eds), Interpretation and method: empirical research methods and the interpretive turn, ME Sharpe, New York.

Yanow, D 2007, ‘Qualitative-Interpretive Methods in Policy Research’, in F Fischer, GJ Miller \& MS Sidney (eds), Handbook of Policy Analysis: Theory, Politics and Methods, CRC Press, Boca Raton.

Yanow, D 2009, 'Dear author, dear reader: the third hermeneutic in writing and reviewing ethnography’, in E Schatz (ed.), Political Ethnography, Chicago, University of Chicago Press. 